\title{
PERFIL DO CONSUMIDOR DE LEITE NO VALE DO RIO SÃO FRANCISCO, PERNAMBUCO
}

\author{
CAMUEl Vieira LiRO ${ }^{1}$, RACKel EMmilly PARENTE GRANJA ${ }^{1}$, FerNANDO ZOCCHE $^{2}$ \\ ${ }^{1}$ Graduandos do curso de Medicina Veterinária da Universidade Federal do Vale do São Francisco, Petrolina, PE. \\ ${ }^{2}$ Professor da Universidade Federal do Pampa, Dom Pedrito, RS. fernandozocche@unipampa.edu.br
}

\begin{abstract}
No Brasil, o leite in natura (leite cru) é um dos principais produtos agropecuários, devido principalmente ao seu elevado comércio e consumo. O crescimento desse comércio e consumo está relacionado com a importância econômica e nutricional que esse produto representa, pois, além de gerar empregos e renda, o leite desempenha um importante papel na alimentação humana. Uma das consequências do consumo de leite in natura é a possibilidade de veicular doenças transmitidas por alimento. Este trabalho teve como objetivo elucidar os hábitos de consumo de leite e de leite in natura dos habitantes do município de Petrolina, localizado no Vale

do Rio São Francisco, Pernambuco. Para tanto, foi utilizado um método de pesquisa descritiva baseado na observação dos eventos buscando a resolução de problemas por meio da observação, análise e descrições objetivas, através de entrevistas com peritos. O hábito dos consumidores de leite na cidade de Petrolina-PE é bastante variado, sendo $26,6 \%$ dos entrevistados consumidores de leite in natura. É necessária a orientação das pessoas para a reduzida qualidade do leite in natura e o combate à comercialização e consumo do mesmo, adotando-se medidas para impedir a venda clandestina, garantindo a segurança dos alimentos e dos consumidores.
\end{abstract}

PALAVRAS-CHAVE: hábito de consumo; leite cru; doenças transmitidas por alimentos.

\section{PROFILE OF MILK CONSUMERS IN SAO FRANCISCO VALLEY, PERNAMBUCO, BRAZIL}

\section{ABSTRACT}

Fresh milk (raw milk) is one of the main agricultural products in Brazil, due mainly to its high trade and consumption. The growth of trade and consumption is related to the nutritional and economic importance of this product, because, besides generating jobs and income, milk plays an important role in human nutrition. One of the consequences of the consumption of raw milk is the possibility of contracting food-borne diseases. This study aimed to elucidate the consumption habits of milk and raw milk of the inhabitants of the the city of Petrolina, located in Vale do Rio São Francisco, Pernambuco, Brazil. For this, we used a descriptive research method based on observation of events seeking to solve problems through observation, analysis and objective descriptions, using interviews with experts. The habit of milk consumers in the city of Petrolina is quite varied with $26.6 \%$ of respondents consuming raw milk. It is necessary to guide people to the low quality of raw milk and to combat its marketing and consumption, seeking to prevent illegal sales, ensuring food safety and consumer protection.

KEYWORDS: food-borne diseases; habits of consumption; raw milk. 


\section{INTRODUÇÃO}

O Regulamento da Inspeção Industrial e Sanitária de Produtos de Origem Animal (BRASIL, 1952) define leite, sem outra especificação, como o produto oriundo da ordenha completa e ininterrupta, em condições de higiene, de vacas sadias, bem alimentadas e descansadas. Segundo esse mesmo regulamento, é obrigatório o processamento térmico desse alimento para fins de consumo humano. Pasteurização é o nome dado ao processamento térmico ao qual o leite é submetido e que, na sua forma rápida (HTST), sofre um aquecimento a uma temperatura que varia de 72 a $75{ }^{\circ} \mathrm{C}$, durante 15 a 20 segundos. É um processo suficiente para a destruição da totalidade de microrganismos patogênicos e grande maioria dos deteriorantes (TRONCO, 2010), garantindo, dessa forma, a segurança desse alimento para seus consumidores.

Denomina-se leite cru ou leite in natura aquele leite que não sofreu o processamento térmico adequado (BRASIL, 2002), ou seja, é aquele leite que não tem garantia de isenção de patógenos e que, se consumido, pode resultar em doença, as chamadas doenças transmitidas por alimentos (DTAs).

Estima-se que no Brasil o consumo de leite in natura seja em torno de 50\% (RIOS ESTUDOS E PROJETOS citado por NERO et al., 2003). No entanto, o sistema de informação referente ao consumo de leite in natura ainda é bastante deficiente, subestimando, muitas vezes, os índices reais. O crescimento da produção e comercialização do leite informal no Brasil cresceu consideravelmente nos últimos anos (RIOS ESTUDOS E PROJETOS citado por NERO et al., 2003). Esse crescimento é preocupante, pois cresce também o consumo de produtos lácteos clandestinos, configurando em grave problema de saúde pública. A informalidade, má higienização, inadequado acondicionamento e transporte, bem como ausência da refrigeração, são fatores que condicionam a proliferação e ação de microrganismos causadores de doenças e que, consequentemente, acometem a população consumidora de leite in natura e seus derivados.

Estudos conduzidos em pequenas e médias cidades geralmente são mais eficientes por aproximarem-se da realidade do comércio e consumo desse tipo de leite (NERO et al., 2003). Nesse aspecto, é de fundamental importância o conhecimento do perfil da população consumidora de leite para que possam ser implantados e implementados programas de orientação de consumo de produtos lácteos, bem como programas de capacitação de manipuladores de alimentos, comerciantes e pequenos produtores. Com estudos dessa natureza, auxilia-se também o direcionamento de ações mais efetivas de órgãos de fiscalização, para o monitoramento, controle e combate de produtos de origem animal clandestinos. O intuito é auxiliar a disseminação de informações aos órgãos oficiais fiscalizadores/reguladores para maior eficiência no controle desse mercado informal, além de auxiliar programas de conscientização da população.

Assim, este trabalho teve como objetivo elucidar os hábitos de consumo de leite e de leite in natura (cru) dos habitantes do município de Petrolina, localizado no Vale do Rio São Francisco, Pernambuco.

\section{MATERIAL E MÉTODOS}

A pesquisa realizada neste estudo é classificada como descritiva e teve por premissa buscar a resolução de problemas melhorando as práticas através da observação, análise e descrições objetivas, por meio de entrevistas com peritos, para a padronização de técnicas e validação de conteúdo (THOMAS et al., 2007). Usaram-se, neste estudo, padrões textuais como, por exemplo, um questionário para identificação do conhecimento, que teve por finalidade observar, registrar e analisar os fenônemos sem, entretanto, entrar no mérito de seu conteúdo. Na pesquisa descritiva, não houve interferência do investigador, que apenas procurou perceber, com o necessário cuidado, a frequência com que o fenômeno acontecia (SILVA, 2003).

Durante os meses de setembro de 2009 a janeiro de 2010, foram entrevistados 583 domicílios particulares permanentes em 13 distintos bairros do município de Petrolina, PE, a seguir: Areia Branca, Centro, José e Maria, São Gonçalo, Alto da Boa Vista, Cohab Massangano, São José, Loteamento Recife, Vila Eduardo, Gercino Coelho, Vila Mocó, Caminho do Sol e Atrás da Banca. Foram selecionados, aleatoriamente, bairros próximos e bairros distantes do centro da cidade, como forma de obter a amostragem mais representativa o possível dentro do município.

O perfil do consumidor foi estabelecido por meio do questionário adaptado de NERO et al. (2003) e que pode ser visualizado na Figura 1. 


\section{INFORMAÇÕES GERAIS}

Questionário

1. Nome:

2. Endereço:

Bairro:

3. Grau de escolaridade:

4. Quantas pessoas moram nessa residência:

\section{INFORMAÇÕES SOBRE O CONSUMO DE LEITE}

5. Consome leite?

6. Qual o destino do leite?

7. Tipo de leite que consome?

$\operatorname{sim}$

não
A B Past eurizado
8. O consumo é diário?
UAT
$\operatorname{sim}$

vaca

9. Quantos litros consomem por dia?

10. Armazena o leite em geladeira? sim

11. Tem o hábito de ferver o leite antes de consuniro

12. Quanto tempo o leite permanece viável na geladeira?

13. Sabe que existem doenças transmitidas pelo leite?

14. Que nota você atribui para a qualidade do leite em Petrolina? $\quad$ 0, 1, 2, 3, 4 ou 5

\section{INFORMAÇÕES SOBRE O CONSUMO DE LEITE CRU}

15. Sabe o que é leite cru?

16. Consome leite cru? $\operatorname{sim}$ não

17. Por que consome leite cru?

18. Qual o destino do leite cru?

19. Ferve o leite cru antes do consumo? sim não

20. Por quanto tempo ferve o leite cru?

21. Conhece alguma doença que o leite cru pode causar?

22. Caso faça derivados, qual o destino?

\section{INFORMAÇÕES SOBRE A ORIGEM DO LEITE CRU}
23. É entregue em casa? sim
não
24. Caso não seja entregue em casa, onde é adquirido?
25. Horário de entrega do leite cru em casa?
26. Frequiência de entrega do leite cru?
27. Acondicionamento do leite cru?
28. O leite cru é entregue em mãos? sim não
29. Conhece a origem do leite cru?
30. "Confia" em quem entrega/vende o leite cru?
31. Conhece alguma lei que proíba a venda de leite cru?

Figura 1: Questionário aplicado aos moradores de Petrolina, PE, para estabelecer o perfil do consumidor de leite.

O questionário continha perguntas que buscavam obter dados sobre aspectos distintos do consumo de leite. Foram obtidos dados sobre as opiniões e ações de pessoas, relativos ao consumo de leite em geral e também do leite in natura.

\section{RESULTADOS E DISCUSSÃO}

A pesquisa foi realizada procurando se ater às respostas relacionadas aos consumidores de leite $\mathrm{e}$ seus derivados. Buscou-se, com isso, obter as características desses consumidores, a frequência do 
consumo desses produtos em sua residência, como também o local em que era comprado e o conhecimento dos consumidores em relação às doenças transmitidas pelo leite e seus derivados.

$O$ total de residências abordadas $(n=583)$ representa $0,72 \%$ do total de domicílios particulares ocupados no município de Petrolina (IBGE, censo demográfico 2010). Considerando que cada residência possui, em média, 3,64 moradores (IBGE, censo demográfico 2010), foram atingidas 2122 pessoas.

Das 583 residências entrevistadas, 567 $(97,25 \%)$ eram consumidoras de leite e 16 (2,74\%) não o consumiam pelos seguintes motivos: intolerância a lactose $(n=2)$, "alergias” $(n=2)$, preço elevado $(n=4)$ e não gostam $(n=8)$.

$\mathrm{O}$ leite adquirido pelos consumidores na cidade de Petrolina, PE, teve como principal destino o consumo direto $(97,9 \%)$. Esse resultado é similar ao descrito por NERO et al. (2003) que, avaliando hábitos de consumidores de leite do município de Campo Mourão, PR, detectaram que 95,07\% dos moradores utilizavam o leite como bebida.

Observou-se que, em algumas residências entrevistadas, mais de um destino foi dado ao leite, cujos fins podem ser observados na Tabela 1.

Tabela 1 - Destino do leite dado pelos consumidores do município de Petrolina-PE

\begin{tabular}{ccc}
\hline Destino do leite & $\begin{array}{c}\text { Quantidade de } \\
\text { residências* }\end{array}$ & (\%)* \\
\hline Consumo direto & 555 & 97,90 \\
Ingrediente para bolo & 93 & 16,40 \\
Vitamina & 33 & 5,82 \\
Doce de leite & 17 & 3,00 \\
Coalhada & 11 & 1,94 \\
Mingau & 10 & 1,80 \\
Queijo & 10 & 1,80 \\
Sorvete & 4 & 0,70 \\
\hline
\end{tabular}

* Mais de um destino foi dado ao leite em uma mesma residência.

Com relação à frequência de consumo, 437/567 (77,1\%) residências consumidoras de leite o consumiam diariamente e 82/567 (14,5\%) não consumiam todos os dias. Os distintos tipos de leite consumidos no município de Petrolina, PE, estão demonstrados na Figura 2.

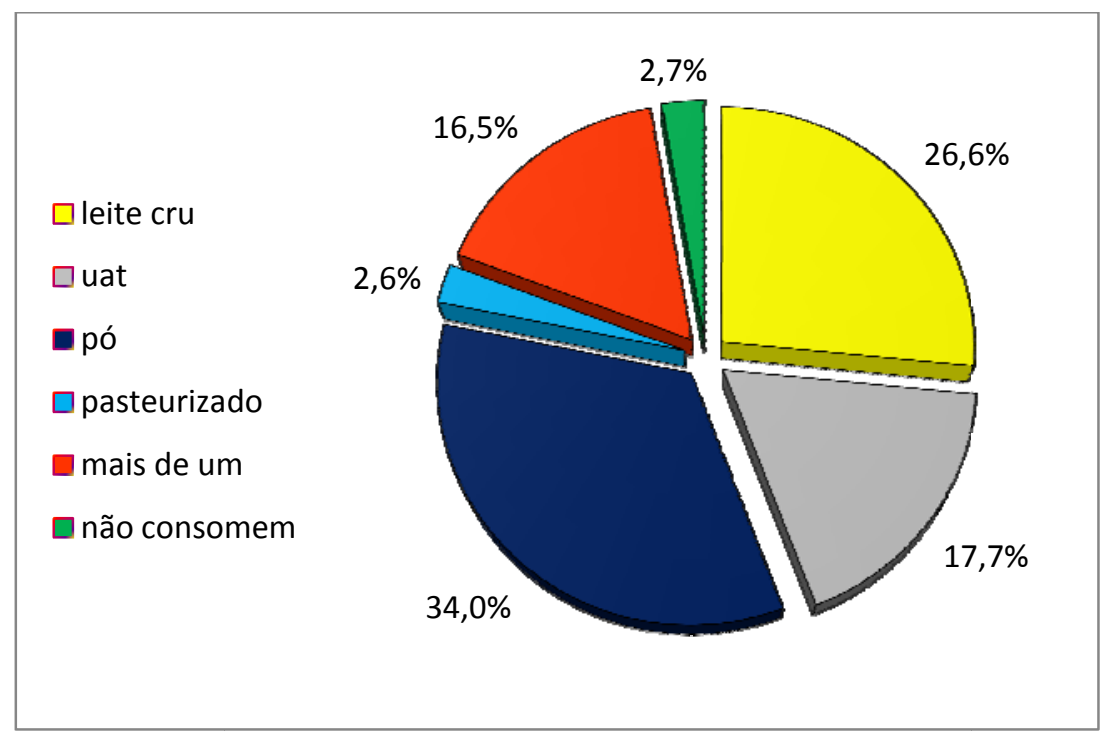

Figura 2. Percentual dos tipos de leite consumidos na cidade de Petrolina-PE.

Analisando os resultados obtidos neste estudo, é possível observar realidades similares a outras regiões do país, como a evidenciada em Campo Mourão, PR, onde NERO et al. (2003) observaram que $33,57 \%$ da população consumiam leite in natura (cru), e na região de Colatina, ES, em que $34,59 \%$ dos populares eram consumidores de produtos lácteos de origem informal (MILLER,
2008).

Do total de domicílios consumidores de leite, 273/567 (48,14\%) consumiam leite fluido (in natura, pasteurizado, UAT). A quantidade de leite, em litros, consumida diariamente foi de meio litro (57/567) (10,05\%); 1 litro (129/567) (22,75\%); 2 litros (68/567) (12\%); 3 litros (12/567) (2,11\%) e 4 litros (7/567) $(1,23 \%)$. 
O conhecimento sobre doenças transmitidas por alimentos e sobre métodos de armazenamento e consumo de produtos de origem animal, especialmente o leite, pode influenciar significativamente nos índices das referidas doenças. Parte dos hábitos de consumo de leite e da concepção dos moradores em relação à DTA's, está ilustrada na Tabela 2.

Tabela 2- Conhecimento sobre doenças transmitidas por alimentos e hábitos de consumo e armazenamento de leite na cidade de Petrolina-PE

\begin{tabular}{ccccccc}
\hline & \multicolumn{3}{c}{ Leite (UAT e/ou pasteurizado) } & \multicolumn{3}{c}{ Leite in natura } \\
\cline { 2 - 6 } $\begin{array}{c}\text { Hábitos de } \\
\text { consumo }\end{array}$ & $\begin{array}{c}\text { Fervura } \\
\mathrm{n}^{*}=330\end{array}$ & $\begin{array}{c}\text { Armazenamento } \\
\text { em geladeira } \\
\mathrm{n}^{*}=361\end{array}$ & $\begin{array}{c}\text { Conhecimentos } \\
\text { sobre DTA's } \\
\mathrm{n}^{*}=509\end{array}$ & $\begin{array}{c}\text { Consome } \\
\text { leite in } \\
\text { natura } \\
\mathrm{n}^{*}=583\end{array}$ & $\begin{array}{c}\text { Fazem } \\
\text { derivados com } \\
\text { leite in natura } \\
\mathrm{n}^{*}=155\end{array}$ & $\begin{array}{c}\text { Fervura } \\
\mathrm{n}^{*}=144\end{array}$ \\
\hline \multirow{2}{*}{$\mathrm{SIM}$} & 189 & 232 & 309 & 155 & 72 & 138 \\
& $(57,27 \%)$ & $(64,26 \%)$ & $(60,7 \%)$ & $(26,58 \%)$ & $(46,45 \%)$ & $(95,83 \%)$ \\
NÃO & 141 & 129 & 200 & 428 & 83 & 6 \\
& $(42,73 \%)$ & $(35,74 \%)$ & $(39,3 \%)$ & $(73,42 \%)$ & $(53,55 \%)$ & $(4,17 \%)$ \\
\hline
\end{tabular}

* O número de amostras refere-se apenas ao número de respostas observadas no estudo.

Com relação ao leite in natura, 138/144 $(95,83 \%)$ da população consumidora desse alimento possuíam o hábito de fervê-lo antes do consumo, resultado que se aproxima dos observados no estudo realizado por NERO et al. (2003) em Campo Mourão, PR, onde 97,89\% da população possuía o hábito de ferver o leite. Considerando o total de residências consumidoras de leite UAT e/ou pasteurizado, 189/330 (57,27\%) tinham o hábito de ferver o leite antes de ser consumido e 141/330 (42,73\%) não tinham esse hábito (Tabela 2). Os processos tecnológicos aos quais o leite é submetido (pasteurização ou ultra alta temperatura) são suficientes para a eliminação total de patógenos, o que dispensa a fervura desse tipo de leite pelo consumidor.

$$
\text { Além disso, 232/361 (64,26\%) }
$$

armazenavam o leite em geladeira, lá permanecendo por 1 dia em 80/361 (22,2\%) residências, 2 dias em 79/361 (22\%) residências, 3 dias em 2/361 (0,55\%) residências, 4 dias em 8/361 (2,22\%) residências, 7 dias em 18/361 (5\%) residências, 14 dias em 1/361 (0,3\%) residência e até mesmo 30 dias em $1 / 361$ (0,3\%) residência, enquanto $129 / 361$ (35,74\%) disseram que não armazenavam o leite na geladeira. Considerando que o leite após aberto deve permanecer por, no máximo, 3 dias na geladeira, os resultados obtidos neste estudo são preocupantes, já que aquele leite que ultrapassar esse prazo bem como aquele não armazenado sob frio poderão sofrer deterioração microbiana e veicular doença.

Embora 97,25\% dos entrevistados tenham o hábito de consumir leite (UAT, pasteurizado, in natura, em pó) em Petrolina, PE, apenas 309/509 $(60,7 \%)$ afirmam saber que existem doenças transmitidas por esse alimento, enquanto 200/509 (39,3\%) afirmaram não conhecer doenças que possam ser transmitidas pelo alimento. Os resultados referentes ao conhecimento de doenças veiculadas pelo leite são inferiores aos relatados por NERO et al. (2003), que constataram que 68,09\% dos moradores de Campo Mourão, PR, fervem o leite buscando a destruição de patógenos, porém os resultados do presente estudo são superiores aos valores encontrados por SOUZA, (2005) e MILLER (2008), que relataram que $40,7 \%$ e $37,96 \%$, respectivamente, dos moradores entrevistados nas cidades de Jacareí, SP, e Colatina, ES, sabiam da existência de doenças transmitidas pelo leite. Esses dados são preocupantes, pois pouco menos da metade das pessoas entrevistadas tem conhecimento de que o leite pode ser um veículo de transmissão de doenças e um elevado percentual (26,6\%) é consumidora de leite in natura.

Em relação às notas atribuídas ao leite comercializado em Petrolina, PE, foram atribuídos os seguintes conceitos: 0 = péssimo, 1 = ruim, 2 = regular, $3=$ bom, $4=$ ótimo e $5=$ excelente. Os resultados atribuídos pelos moradores estão ilustrados na Figura 3. 


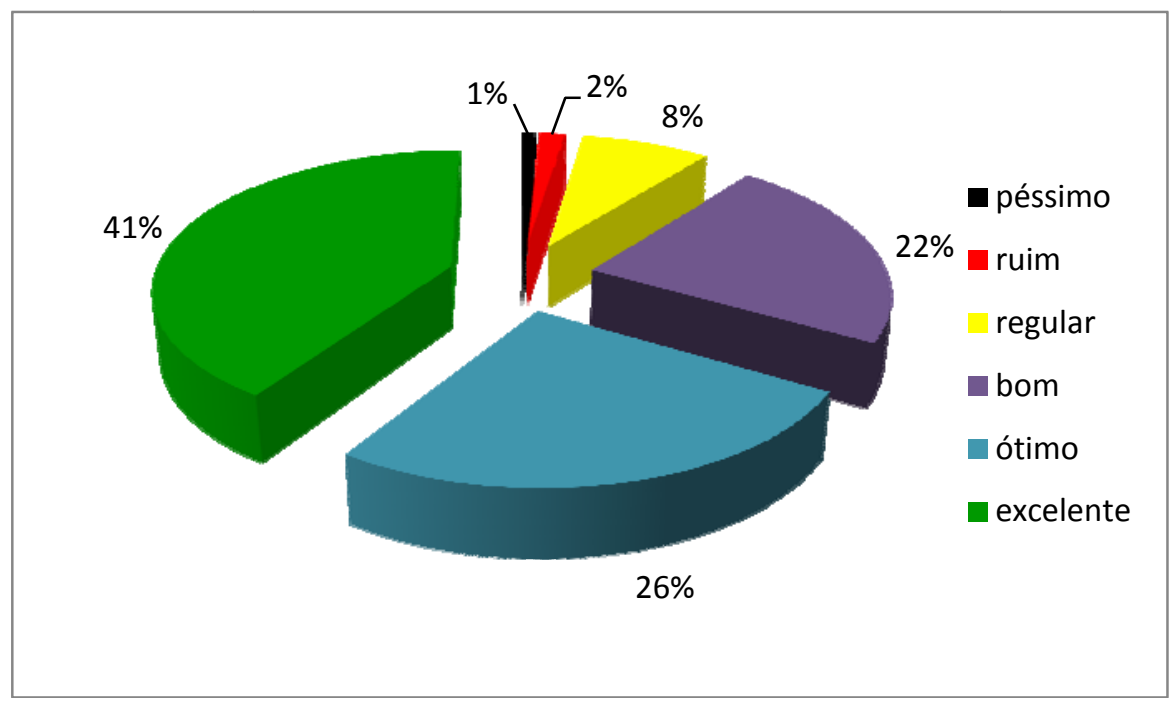

Figura 3. Notas atribuídas com relação à qualidade do leite na cidade de Petrolina-PE.

Dos 583 domicílios entrevistados, 155 $(26,59 \%)$ afirmaram consumir leite in natura e 428 (70,67\%) consumiam outros tipos de leite.

Considerando os consumidores de leite in natura, 116/155 (74,83\%) disseram que sabiam o que era esse leite e que o consumiam por ser mais gostoso em 62/155 (40\%), ser bom para algumas receitas em 6/155 (13,87\%), mais saudável em 17/155 (10,9\%), mais nutritivo em 6/155 (3,87\%), de menor custo em 5/155 (3,22\%), "por tradição" em 4/155 (2,58\%), porque “tira da fazenda” em 4/155 (2,58\%), mais forte em 3/155 (1,93\%), bom para fazer coalhada em 3/155 (1,93\%), mais gorduroso em 2/155 (1,29\%), bom para os ossos em 2/155 $(1,29 \%)$ e por comodidade em 1/155 (0,64\%). Em 32/155 (20,64\%) residências entrevistadas afirmouse não saber o que é leite cru, mas que ele é consumido mesmo assim. Os resultados correspondentes ao consumo são distintos dos obtidos por NERO et al. (2003), que observaram que os moradores de Campo Mourão, PR, afirmam consumir o leite devido ao menor custo (40,85\%) e por ser mais forte (40,14\%). Ainda, SOUZA (2005) também observou na cidade de Jacareí, SP, que as principais respostas com relação ao consumo são "menor custo" e "mais forte". É interessante ressaltar que, neste estudo, três consumidores compram e consomem leite in natura por ser melhor para fazer coalhada. Esse dado corrobora com a informação de que o leite in natura na cidade de Petrolina possui uma microbiota intrínseca acidificante elevada e que a multiplicação intensa desses microrganismos contribui significativamente para fermentação de carboidrato e consequente produção de ácido lático, com a precipitação protéica, semelhante à tecnologia de fabricação típica da coalhada.

Dentre os consumidores de leite in natura, 62/155 (40\%) o destinavam para consumo direto e $58 / 155$ (37,41\%) para fazer derivados e/ou outros alimentos. Aqueles que faziam derivados e/ou outros alimentos, o utilizavam para fazer bolo 30/155 (19,35\%), coalhada 24/155 (15,48\%), doce de leite 9/155 (5,80\%), vitamina 4/155 (2,58\%), queijo 4/155 $(2,58)$ e manteiga $1 / 155(0,64 \%)$. Além disso, 2/155 $(1,29 \%)$ dos domicílios afirmaram comprar o leite para revenda.

Com relação à fervura, 138/144 (95,83\%) afirmaram ferver o leite antes de consumi-lo e 6/144 $(4,17 \%)$ não ferviam. Os que ferviam o leite enfatizaram que deixavam o leite ferver até subir em 83/144 (57,63\%) residências, por 1 minuto em 1/144 $(0,7 \%)$, por 3 minutos em $2 / 144$ (1,38\%), entre $5-10$ minutos em 23/144 (16\%), até subir duas vezes em 9/144 (6,25\%) e entre 20-30 minutos em 11/144 (7,63\%). Vale ressaltar o fato de somente 35/155 (22,58\%) domicílios responderem positivamente para o conhecimento sobre alguma doença que o leite possa transmitir e 109/155 (70,32\%) não conhecerem nenhuma doença transmitida pelo leite e derivados.

Durante muito tempo utilizou-se fervura para prolongar a vida de prateleira do leite, mas, posteriormente, essa operação fundamental foi utilizada apenas para evitar a disseminação de doenças que poderiam ser transmitidas pelo consumo do leite in natura. Muito embora os microrganismos patogênicos sejam destruídos com a fervura, também são destruídas com o processo várias enzimas e parte 
das propriedades e características do alimento. Desse modo, para eliminação de patógenos devem ser considerados outros métodos, tais como os citados pela legislação brasileira: pasteurização ou utilização de ultra altas temperaturas (leite UAT) (TRONCO, 2010).

Quanto a origem do leite in natura, e considerando os consumidores desse tipo de leite, 59/155 (38\%) dos entrevistados afirmaram receber o produto na própria residência e 85/155 (54,83\%) afirmaram não receber o produto na residência, sendo adquirido em distintos locais, explicitados na Figura 4.

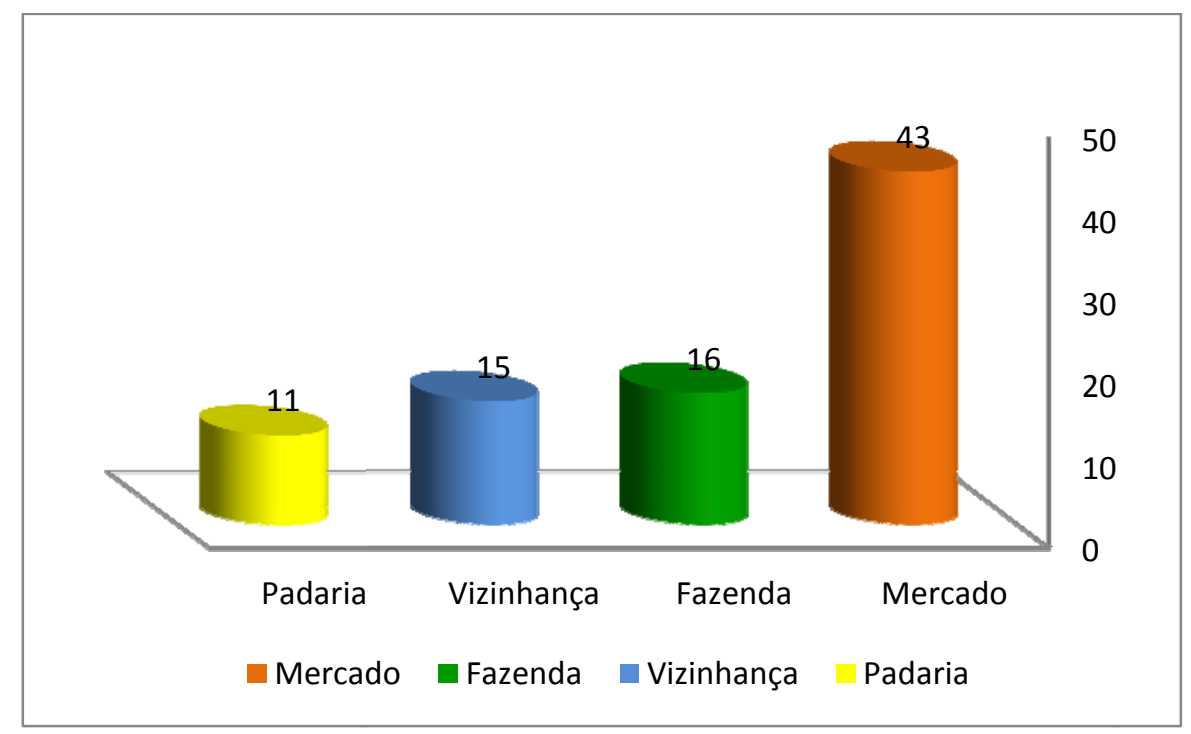

Figura 4. Local onde é adquirido o leite in natura no município de Petrolina, PE, representados em número absoluto.

MILLER (2008) afirma em seu estudo que o local onde o leite in natura é adquirido com maior frequência $(70,79 \%)$ é em supermercados, índice distinto dos obtidos nessa pesquisa. Embora o comércio de leite in natura seja proibido pela legislação brasileira, é fácil encontrar esse alimento em pequenos mercados, como evidenciado neste estudo. A presença desse alimento em pequenos estabelecimentos comerciais pode ser explicada pela desinformação que existe entre os proprietários que não sabem da proibição do comércio, bem como pela procura da população que, desavisadamente, procura e adquire um produto de qualidade inferior imaginando ser "mais gostoso" ou "mais adequado para algumas receitas".

O horário de entrega do leite in natura está demonstrado na Tabela 3.

Tabela 3 - Horário de entrega do leite in natura nas residências de Petrolina-PE

\begin{tabular}{ccc}
\hline Horário de entrega do leite in natura nas residências & Quantidade de domicílios & $(\%)$ \\
\hline $5: 00-6: 00$ & 2 & 2,70 \\
$7: 00$ & 5 & 6,75 \\
$8: 00$ & 14 & 18,9 \\
09:00-10:00 & 13 & 17,6 \\
$10: 00-11: 00$ & 11 & 14,9 \\
11:00-12:00 & 6 & 8,1 \\
Manhã & 11 & 14,9 \\
Tarde & 12 & 16,2 \\
\hline TOTAL & $74^{*}$ & 100
\end{tabular}

*Apenas 74 pessoas sentiram-se confiantes para dizer o horário da entrega do leite in natura. 
Uma das características do município de Petrolina, PE, é o clima quente seco. A temperatura média do ar no ano de 2009 foi de $25,9{ }^{\circ} \mathrm{C}$, tendo temperatura máxima de $32,4{ }^{\circ} \mathrm{C}$ no mesmo ano (EMBRAPA, 2010). Este estudo foi desenvolvido nos meses de outubro de 2009 a janeiro de 2010, meses em que as temperaturas são geralmente acima da média do município. Considerando o exposto, vale ressaltar que, mesmo em condições de altas temperaturas, um elevado percentual $(3,87 \%)$ de moradores adquiria o leite num horário avançado (entre 11 e $12 \mathrm{~h}$ ).

A periodicidade de aquisição de leite in natura está demonstrada na Tabela 4.

Tabela 4 - Periodicidade de aquisição de leite in natura no município de Petrolina-PE

\begin{tabular}{ccc}
\hline Frequência de entrega do leite in natura & Quantidade de domicílios & $(\%)$ \\
\hline Diariamente & 50 & 42,4 \\
Três vezes por semana & 23 & 19,5 \\
Duas vezes por semana & 20 & 17 \\
Uma vez por semana & 16 & 13,5 \\
Uma vez por mês & 5 & 4,2 \\
A cada 15 dias & 4 & 3,4 \\
\hline TOTAL & 118 & 100 \\
\hline
\end{tabular}

Com relação ao acondicionamento do leite in natura, $47 \%$ dos consumidores afirmaram adquirir esse alimento acondicionado em garrafa PET. As diferentes formas de acondicionamento de leite in natura no município de Petrolina, PE, podem ser observadas na figura 5.

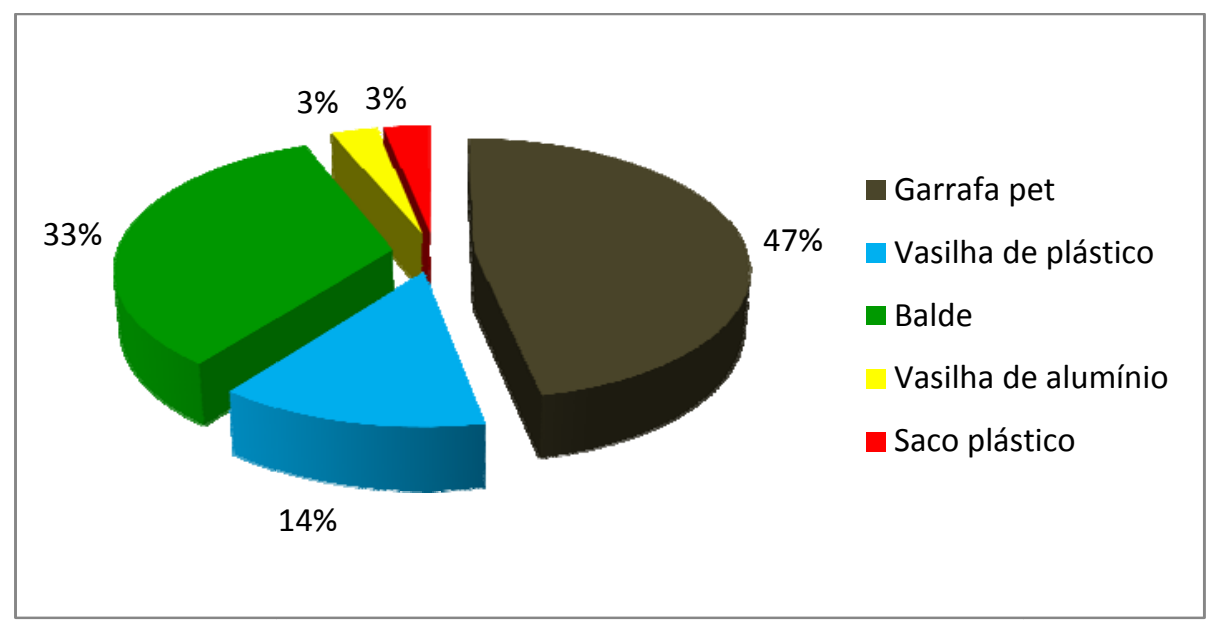

Figura 5. Acondicionamento do leite in natura comercializado em Petrolina, PE.

Ainda com relação ao consumo do leite in natura, 121/155 (78\%) dos domicílios entrevistados afirmaram que o leite é entregue em mãos. Os resultados correspondentes a entrega do leite são distintos daqueles obtidos por NERO et al. (2003), que observaram, em seu trabalho, que $95,78 \%$ dos entrevistados afirmaram que o leite é entregue em mãos.

Neste estudo, a maioria 84/155 (54,2\%) dos entrevistados desconhecia a origem do leite in natura, $\quad 102 / 155 \quad(65,8 \%)$ confiavam no entregador/vendedor do leite in natura e 141/155 (91\%) dos entrevistados desconheciam qualquer lei de proibição do consumo direto de leite in natura. As informações concernentes à origem do leite in natura, confiança no entregador e alguma lei que proíba a venda de leite in natura foram correspondentes a: $57,70 \%$ dos domicílios 
desconheciam o local de produção do leite, 71,83\% confiavam no entregador/vendedor e $83,80 \%$ desconheciam qualquer lei de proibição do comércio direto de leite in natura, índices similares aos observadas por NERO et al., (2003).

\section{CONCLUSÃO}

O hábito dos consumidores de leite na cidade de Petrolina-PE é bastante variado sendo que 26,6\% dos entrevistados são consumidores de leite in natura.

É necessária a orientação das pessoas para a reduzida qualidade do leite in natura e o combate à comercialização do mesmo, adotando-se medidas para impedir a venda clandestina, garantindo a segurança dos alimentos e dos consumidores.

\section{AGRADECIMENTO}

Ao CNPq pela bolsa de Iniciação Científica.

\section{REFERÊNCIAS}

BRASIL. Ministério da Agricultura, do Abastecimento e da Reforma Agrária. Departamento Nacional de Inspeção de Produtos de Origem Animal. Regulamento de Inspeção Indústria e Sanitária de Produtos de Origem Animal. Aprovado pelo Decreto 30.691 de 29 de março de 1952. Rio de Janeiro. 1952. Alterado pelo Decreto 29.093, de 30/04/1956, Decreto 1.255, de 25/06/1962, Decreto 1.236, de 02/09/1994, Decreto 1.812, de 08/02/1996, Decreto 2.244, de 04/06/1997 e Decreto 6.385 de $27 / 02 / 2008$.
BRASIL. Instrução Normativa no $\mathbf{5 1}$, de 18 de setembro de 2002. Aprova os Regulamentos Técnicos de Produção, Identidade e Qualidade do Leite tipo A, do Leite tipo B, do Leite tipo C, do Leite Pasteurizado e do Leite Cru Refrigerado e o Regulamento Técnico da Coleta de Leite Cru Refrigerado e seu Transporte a Granel. Diário Oficial da União, Brasília, p.13, 21 set. 2002. Seção 1.

EMBRAPA SEMI-ÁRIDO. Médias Anuais da Estação Agrometeorológica de Bebedouro (Petrolina-PE 09 09'S, $4^{\circ}{ }^{\circ} 22 ' W$ ). Período 1975-2009. Disponível em http://www.cpatsa.embrapa.br:8080/servicos/dadosmet/ce b-anual.html. Acesso em 15 set. 2010.

MILleR, N. B. Perfil do consumidor de leite e derivados lácteos do município de Colatina - ES. Instituto Brasileiro de Pós-Graduação Qualittas, Abril de 2008.

NERO, L. A., MAZIERO, D., BEZERRA, M. M. S. Hábitos alimentares do consumidor de leite cru de Campo Mourão - PR. Semina: Ciências Agrárias, Londrina, v.24, n.1, p.21-26, 2003.

SOUZA, D. D. P. Consumo de produtos lácteos informais, um perigo para saúde pública. Estudo dos fatores relacionados a esse consumo no município de Jacareí-SP. Faculdade de Medicina veterinária e Zootecnia, Universidade de São Paulo, 2005.

SILVA, Antônio Carlos Ribeiro de. Metodologia de pesquisa aplicada à contabilidade: orientações, projetos, monografias, dissertações, teses. São Paulo: Atlas, 2003.

THOMAS, J. R.; NELSON, J. K.; SILVERMAN, S.J. Métodos de pesquisa em atividade física.5.ed. Porto Alegre: Artmed, 2007.

TRONCO, V. M. Manual para inspeção da qualidade do leite. $4^{\text {a }}$ ed., Santa Maria. Editora da UFSM, 2010. 206p. 